Ivana M. Ilić1

\title{
RELATIONSHIPS OF WORK-RELATED PSYCHOSOCIAL RISKS, STRESS, INDIVIDUAL FACTORS AND BURNOUT - QUESTIONNAIRE SURVEY AMONG EMERGENCY PHYSICIANS AND NURSES
}

\author{
${ }^{1}$ Institute for Occupational Safety and Health Niš, Niš, Serbia \\ ${ }^{2}$ University of Niš, Niš, Serbia \\ Faculty of Medicine
}

\begin{abstract}
Background: Psychosocial risks represent a great challenge for safety and health protection at work in Europe. The purpose of this study has been to determine the relationships of psychosocial risks arising from work, stress, personal characteristics and burnout among physicians and nurses in the Emergency Medical Service (EMS). Material and Methods: We performed a cross-sectional study based on a questionnaire survey which contained the Copenhagen Psychosocial Questionnaire (COPSOQ) and Copenhagen Burnout Inventory (CBI). Results: A total of 88 physicians and 80 nurses completed the survey. Physicians demonstrated higher emotional (mean $(M) \pm$ standard deviation $(S D)=74.57 \pm 16.85)$ and cognitive $(\mathrm{M} \pm \mathrm{SD}=75.95 \pm 13.74)$ demands as compared to nurses. Both groups had high sensory demands and responsibilities at work, in spite of the low degree of their autonomy. The meaning of work, commitment to the workplace, and insecurity at work were high for both groups. Among all participants, stressful behavior and reactions were within the limits of low values $(<40)$ and coping strategies showed high values $(>60)$. Personal and patient-related burnout was high for both groups, where physicians were significantly affected by work-related burnout. The influence at work, degree of freedom at work, social support, sense of coherence, mental health, and problem-focused coping are negatively related to work-related burnout. Conclusions: Based on personal factors and coping styles, emergency physicians and nurses are representing a self-selective professional group that meets high work demands, great responsibility, strong commitment and insecurity at work. Burnout of physicians and nurses in the EMS tends to be ignored, although it has severe consequences on their mental and general health. Med Pr 2017;68(2):167-178
\end{abstract}

Key words: burnout, psychosocial risks, emergency physicians/nurses, COPSOQ, CBI, occupational stress

Corresponding author: Ivana Ilić, Institute for Occupational Safety and Health Niš, Vojislava Ilića bb., 18000 Niš, Serbia, e-mail: ivanailic.md@gmail.com

Received: May 31, 2016, accepted: October 25, 2016

\section{INTRODUCTION}

The part of the job position is placed among the most fundamental life's categories and it influences the success and quality of life, providing support, stronger sense of social inclusion, identity, status, possibility for development and increasing trust.

In recent decades, work has been characteristic of profound changes in regard to the nature of work, working conditions, employees' professional life due to globalization, labor market flexibility, new technologies, the economic crisis and recession.

The psychosocial work environment is generally considered to be one of the most important work environment issues in contemporary and future societies. Psychosocial risk factors go hand in hand with the experience of work-related stress. Work-related stress is the response people may have when presented with work demands and pressures that are not matched to their knowledge and abilities and which challenge their ability to cope [1]. Poor psychosocial work environment could have negative effects on health, work ability, and productivity [2]. For these reasons the health and well-being of employees are important issues and numerous studies report more frequent health disorders, mental symptoms and burnout among healthcare professionals [3-5].

Important psychosocial risks within healthcare services in the transition countries are difficulties due to insufficient resources, overload, working standard, increasing bureaucracy, attitudes of patients and their behavior, poor interpersonal relationship among colleagues, management and organizational structures. These factors are outcomes arising from transition 
acquirements such as rationalization, reconstruction, privatization and lack of social support. In addition, permanent patient care, increased responsibility and realization of their needs and demands have different stress outcomes.

According to holistic approach in understanding reactions to stress and confrontation with stressful situations it is important to find out about estimation and emotional experience of stress, namely understanding influences, characteristics and types of psychosocial risks, that is their frequencies, duration, diversity and intensity [6]. Coping with stress involves selection, organization and realization of effective and ineffective ways of reacting to stress, which depends on the subjective and the objective appraisal [7].

Stress reactions are described as consequences of usual daily work duties and engagements at emergency medical services (EMS), and represent an example of these situations. Some physicians' and nurses' routine job in the EMS includes inter alia working under specific circumstances and frequent exposure to human suffering, grief, death and events which are far beyond usual human experience.

Various indicators [8] such as early retirement, higher incidence of cardiovascular, musculoskeletal and malignant diseases, more frequent anxiety-depressive and post-traumatic stress disorders (PTSD), increased mortality, sudden deaths and injuries suggest that employees in the EMS are exposed to higher risk as compared to the general working population and other healthcare employees. This is associated with specific work demands on "the front line" with emphasis on potentially dangerous effects [9] of exposure to excessive stress. Personal predisposition or vulnerability [10] also contributes to the same result but there is a lack of reliable evidence $[8,11]$ about which occupational factors or individual coping styles, personality and psychological resilience could protect and preserve the health of the EMS staff.

Burnout is a chronic process associated with the accumulation of stressors that deplete ideals, motivation, and commitment to the goals of an individual. It is a state of physical, emotional, mental exhaustion and cognitive loss that reflects the belief that resources which a person has to cope with stress are inadequate or non-existent. All of this is caused by a long-term exposure to emotionally demanding situations and interpersonal stressful events at a workplace [12], which are not rare at the emergency department. Kristensen et al. [13] conceptualized burnout as physical and psychological exhaustion which appear during work and life in general context.

Sources and levels of stress and burnout that emergency physicians and nurses experience as well as the value their effectiveness may depend on their work and personal features and the extent to which they apply different coping strategies.

This study addresses these issues by examining the effect of the EMS staffs' psychosocial risks at work and personal characteristics at the level of burnout that they experience from various sources, in addition to their perception of the effectiveness of coping with stress.

\section{MATERIAL AND METHODS}

\section{Study design and participants}

A cross-sectional study comprised the total of 101 physicians and 103 nurses, employed in the EMS in the City of Niš, the Republic of Serbia. The participation in the research was voluntary and anonymous. Out of total, $168(82.35 \%)$ participants, (88 physicians and 80 nurses/technicians) answered all given questions, and the remaining 36 (17.65\%) of questionnaires were not valid for further analysis.

\section{Questionnaires}

For all participants involved in the research a questionnaire survey was put together to contain general data, Serbian translations of the Copenhagen Psychosocial Questionnaire (COPSOQ) [2,14-16] about psychosocial factors at work, health and well-being and inventory about burnout according to the Copenhagen Burnout Inventory (CBI) [13].

The general data related to age, gender, total and specific emergency medical service work experience, marital status, lifestyle, additional works, shifts and night work.

The Copenhagen Psychosocial Questionnaire is a tool developed by the Danish National Research Centre for the Working Environment in Copenhagen, internationally renowned, oriented to evaluation of psychosocial risks at work, that is considered as a standardized instrument for prevention purposes [14,15]. The COPSOQ is theory-based on a set of stress theories more widely nowadays, but not attached to one specific theory. It is a very complete and combined method that covers the main relevant workplace-related factors [16]. The COPSOQ scales developed for assessing a broad variety of work-related factors: psychosocial factors at work, factors in the social work environment, in the 
quantitative, cognitive, emotional and other demands that the work environment and the work itself puts onto people, the personal importance of work, the influence and room for decision that people have in their work environment, their coping styles and sense of coherence on stress and individual health and well being among employees and other job factors like job security and job satisfaction.

There are 3 versions of the COPSOQ questionnaire. In this study, the long (141 questions) Croatian version of the COPSOQ questionnaire $[2,15]$ almost identical to the Serbian language (formerly called Serbo-Croatian) was the dialectical one that had been adjusted after having been developed by its first author. The scales of the COPSOQ are formed by adding the points of the individual questions of the scales by giving equal weights to each question. In most cases, the questions have 5 response options. In these cases the weights are: $0,25,50,75$, and 100 . The scale value is calculated as the simple average. Thus, all scales go from 0 to 100 . The national average score obtained on the basis of testing questionnaires in the Danish population is 50 for all scales. The values of the scale 40-60 are considered average or moderate, and all other higher or lower values are considered to be significantly important.

The Copenhagen Burnout Inventory $[13,17]$ is the specific instrument designed for burnout assessment. It consists of 19 questions divided into 3 parts that are related to personal burnout (6 questions), work-related (7 questions) and patient-related burnout (6 questions). All questions have 5 possible answers. Each of the answer has been assigned a certain number of points: $0,25,50,75$ and 100 . The value of the burnout level is calculated as mean value; therefore, every scale has value $0-100$. The CBI questionnaire is based on the assumption that the state of prolonged physical and psychological exhaustion is a core component for the development of burnout. Personal burnout is defined as a state of exhaustion related to daily life activities. Work-related burnout refers to symptoms of exhaustion which are perceived as related to the person's work, while patientrelated burnout involves exhaustion which is perceived as related to the person's work with patients $[13,17]$. The mean value of the scale indicates the presence of burnout as low if it amounts to fewer than 50 points $(<50)$ and as high if it is above 50 points $(>50)$.

\section{Data analysis}

The data was expressed as mean values $(M)$ and standard deviation (SD). For comparison of mean values between groups, the analysis of variance (ANOVA) and Bonferroni post hoc test were used. Comparison of attributive characteristic frequencies between groups was performed by Mantel-Haenszel Chi ${ }^{2}$ test or Fisher exact test in cases where expected frequency was below 5 . The correlation analysis evaluated the relationship between the scales of the COPSOQ questionnaires and scores of burnout. The calculated Spearman's rank correlation coefficient (r) was evaluated using the Student's t-test. Assessment of factors of interest influencing the total score burnout, the multifactor linear regression analysis (MANOVA) was used. All the statistical analysis was performed using the Statistical Package for Social Sciences (SPSS) version 10.0. (SPSS Inc., USA). In all the analyses $p$ value $<0.05$ is considered statistically significant.

\section{RESULTS}

The main socio-demographic and professional characteristics of participants are shown in the Table 1 . The structure of compared groups by age, gender and marital status were significantly different. More physicians (93.9\%) worked in shifts as compared to $77.5 \%$ of nurses/medical technicians. A similar ratio and significance were registered for night work and work in turns. Nurses worked longer in the EMS $(\mathrm{M} \pm \mathrm{SD}=18.33 \pm 11.30)$ than physicians did (14.40 \pm 8.64$)$.

The results covered Cronbach's a coefficient for the overall scale of the sample $(\mathrm{N}=168)$; the test $(\alpha=0.829)$ revealed a high internal consistency (Table 2); almost all dimensions had Cronbach's a coefficients $>0.6$. The comparison results of Cronbach's a coefficient with the original version [13] of the Denmark sample $(\mathrm{N}=1603$ 1850 ) indicate that our results are similar or higher.

In the Table 3 average values of the COPSOQ scales were presented.

\section{Type of production and tasks}

High emotional $(\mathrm{M} \pm \mathrm{SD}=74.57 \pm 16.85)$ and cognitive $(75.95 \pm 13.74)$ demands for the group of physicians were determined and they were higher than those for nurses $(55.71 \pm 25.25$ and $61.97 \pm 21.06$, respectively). Both of groups had high sensory demands $(81.20 \pm 14.87)$ and (75.18 \pm 22.9$)$. Demands for work responsibility were high for both groups.

\section{Work organization and job contents}

The scales that are related to the dimension "degree of freedom at work" were within the low values for 
Table 1. Characteristics of the study groups in the questionnaire survey on the relationships of work-related psychosocial risks, stress, individual factors and burnout

\begin{tabular}{|c|c|c|c|}
\hline Characteristics & $\begin{array}{l}\text { Physicians } \\
(\mathrm{N}=88)\end{array}$ & $\begin{array}{c}\text { Nurses/ } \\
\text { technicians } \\
(\mathrm{N}=80)\end{array}$ & $\begin{array}{c}\text { Comparison } \\
\text { between } \\
\text { groups }^{*}\end{array}$ \\
\hline Gender [n (\%)] & & & $\mathrm{p}<0.001$ \\
\hline female & $52(59.1)$ & $72(90.0)$ & \\
\hline male & $36(40.9)$ & $8(10.0)$ & \\
\hline Age $[\mathrm{n}(\%)]$ & & & $\mathrm{p}<0.001$ \\
\hline $21-30$ years old & $3(3.4)$ & $24(30.0)$ & \\
\hline $31-40$ years old & $19(21.6)$ & $20(25.0)$ & \\
\hline $41-50$ years old & $48(54.5)$ & $8(10.0)$ & \\
\hline $51-65$ years old & $18(20.5)$ & $28(35.0)$ & \\
\hline Marital status [n (\%)] & & & $\mathrm{p}<0.01$ \\
\hline married & $69(78.4)$ & $42(52.5)$ & \\
\hline living together & $8(9.1)$ & $10(12.5)$ & \\
\hline single & $10(11.4)$ & $20(25.0)$ & \\
\hline divorced & $1(1.1)$ & $8(10.0)$ & \\
\hline Additional works [n (\%)] & & & n.s. \\
\hline yes & $11(12.5)$ & $8(10.0)$ & \\
\hline no & $77(87.5)$ & $72(90.0)$ & \\
\hline Working in shifts [n (\%)] & & & $\mathrm{p}<0.001$ \\
\hline yes & $77(93.9)$ & $62(77.5)$ & \\
\hline no & $5(6.1)$ & $18(22.5)$ & \\
\hline Night work [n (\%)] & & & $\mathrm{p}<0.001$ \\
\hline yes & $74(90.2)$ & $62(77.5)$ & \\
\hline no & $8(9.8)$ & $18(22.5)$ & \\
\hline Working in turns [n (\%)] & & & $\mathrm{p}<0.001$ \\
\hline yes & $74(90.2)$ & $62(77.5)$ & \\
\hline no & $8(9.8)$ & $18(22.5)$ & \\
\hline $\begin{array}{l}\text { Seniority in EMS [years] } \\
(\mathrm{M} \pm \mathrm{SD})\end{array}$ & $14.40 \pm 8.64$ & $18.33 \pm 11.30$ & $\mathrm{p}<0.05$ \\
\hline $\begin{array}{l}\text { Total seniority [years] } \\
(\mathrm{M} \pm \mathrm{SD})\end{array}$ & $18.06 \pm 9.89$ & $19.65 \pm 11.44$ & n.s. \\
\hline
\end{tabular}

EMS - Emergency Medical Service.

M - mean, SD - standard deviation, n.s. - statistically not significant. ${ }^{*} \mathrm{Chi}^{2}$ test.

both groups (physicians: $\mathrm{M} \pm \mathrm{SD}=32.98 \pm 23.54$, nurses: $35.47 \pm 27.62)$. The influence on work was high $(64.80 \pm 14.6)$ in a group of physicians and higher as compared to nurses $(54.19 \pm 17.56)$. High possibilities for career development were determined for physicians $(82.72 \pm 12.36)$ and $65.50 \pm 19.61$ for nurses. Mean-
Table 2. Internal consistency of the Copenhagen Psychosocial Questionnaire (COPSOQ) scales and subscales

\begin{tabular}{|c|c|c|}
\hline \multirow[b]{2}{*}{ COPSOQ scale } & \multicolumn{2}{|c|}{ Cronbach's $\alpha$} \\
\hline & $\begin{array}{l}\text { Serbian } \\
\text { COPSOQ version } \\
\text { from the authors' } \\
\text { study } \\
\quad(\mathrm{N}=168)\end{array}$ & $\begin{array}{c}\text { original } \\
\text { COPSOQ } \\
\text { version }[16] \\
(\mathrm{N}=1603-1850)\end{array}$ \\
\hline Total & 0.83 & 0.76 \\
\hline Quantitative demands & 0.84 & 0.80 \\
\hline Cognitive demands & 0.82 & 0.86 \\
\hline Emotional demands & 0.82 & 0.87 \\
\hline Demands for hiding emotions & 0.83 & 0.59 \\
\hline Sensory demands & 0.82 & 0.70 \\
\hline Responsibility at work & 0.82 & 0.82 \\
\hline Influence at work & 0.82 & 0.83 \\
\hline Possibilities for development & 0.83 & 0.82 \\
\hline Degree of freedom at work & 0.82 & 0.68 \\
\hline Meaning of work & 0.82 & 0.77 \\
\hline Commitment to the workplace & 0.81 & 0.74 \\
\hline Predictability & 0.82 & 0.78 \\
\hline Role clarity & 0.82 & 0.77 \\
\hline Role conflicts & 0.82 & 0.72 \\
\hline Quality of leadership & 0.82 & 0.93 \\
\hline Social support & 0.82 & 0.74 \\
\hline Feedback at work & 0.82 & 0.64 \\
\hline Social relations & 0.83 & 0.65 \\
\hline Sense of community & 0.82 & 0.80 \\
\hline Insecurity at work & 0.83 & 0.61 \\
\hline Job satisfaction & 0.83 & 0.84 \\
\hline General health & 0.82 & 0.75 \\
\hline Mental health & 0.82 & 0.80 \\
\hline Vitality & 0.82 & 0.80 \\
\hline Behavioral stress & 0.82 & 0.79 \\
\hline Somatic stress & 0.84 & 0.76 \\
\hline Cognitive stress & 0.83 & 0.85 \\
\hline Sense of coherence & 0.83 & 0.71 \\
\hline Problem focused coping & 0.83 & 0.75 \\
\hline Emotion focused coping & 0.83 & 0.61 \\
\hline Avoidance/resignation/coping & 0.83 & 0.66 \\
\hline
\end{tabular}

ing of work scales showed high values for both groups but it was significantly higher for the physicians $(79.81 \pm 13.45)$ as compared to nurses $(67.64 \pm 23.30)$. Scales of commitment to the workplace were within

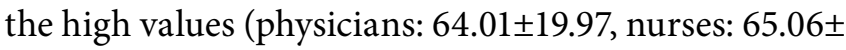
22.24). 
Table 3. Psychosocial factors, health, coping styles and work-related outcome measured by the Copenhagen Psychosocial Questionnaire (COPSOQ) scales [16] in the study groups

\begin{tabular}{|c|c|c|c|}
\hline COPSOQ scale & $\begin{array}{l}\text { Physicians } \\
(\mathrm{N}=88) \\
{[\mathrm{pts}]} \\
(\mathrm{M} \pm \mathrm{SD})\end{array}$ & $\begin{array}{l}\text { Nurses/technicians } \\
\qquad \begin{array}{c}\mathrm{N}=80) \\
{[\mathrm{pts}]} \\
(\mathrm{M} \pm \mathrm{SD})\end{array}\end{array}$ & $\begin{array}{c}\text { Comparison } \\
\text { between groups }\end{array}$ \\
\hline Quantitative demands & $58.61 \pm 9.59$ & $53.90 \pm 9.05$ & $\mathrm{p}<0.01$ \\
\hline Cognitive demands & $75.95 \pm 13.74$ & $61.97 \pm 21.06$ & $\mathrm{p}<0.001$ \\
\hline Emotional demands & $74.57 \pm 16.85$ & $55.71 \pm 25.25$ & $\mathrm{p}<0.001$ \\
\hline Sensory demands & $81.20 \pm 14.87$ & $75.18 \pm 22.90$ & n.s. \\
\hline Responsibility at work & $73.68 \pm 21.84$ & $64.47 \pm 32.49$ & n.s. \\
\hline Influence at work & $64.80 \pm 14.60$ & $54.19 \pm 17.56$ & $\mathrm{p}<0.001$ \\
\hline Possibilities for development & $82.72 \pm 12.36$ & $65.50 \pm 19.61$ & $\mathrm{p}<0.001$ \\
\hline Predictability & $52.66 \pm 18.79$ & $43.03 \pm 21.93$ & $\mathrm{p}<0.05$ \\
\hline Role clarity & $83.26 \pm 13.11$ & $71.31 \pm 22.66$ & $\mathrm{p}<0.001$ \\
\hline Role conflicts & $50.72 \pm 21.78$ & $51.03 \pm 23.77$ & n.s. \\
\hline Quality of leadership & $58.72 \pm 21.38$ & $46.67 \pm 23.52$ & $\mathrm{p}<0.01$ \\
\hline Social support & $60.23 \pm 24.90$ & $48.89 \pm 22.74$ & $\mathrm{p}<0.05$ \\
\hline Feedback at work & $58.68 \pm 31.59$ & $45.36 \pm 26.46$ & $\mathrm{p}<0.05$ \\
\hline Social relations & $64.10 \pm 14.15$ & $66.33 \pm 12.41$ & n.s. \\
\hline Sense of community & $64.84 \pm 21.29$ & $66.25 \pm 23.06$ & n.s. \\
\hline Somatic stress & $35.72 \pm 22.03$ & $37.92 \pm 23.89$ & n.s. \\
\hline Cognitive stress & $32.15 \pm 21.44$ & $37.22 \pm 23.84$ & n.s. \\
\hline Sense of coherence & $54.02 \pm 14.99$ & $53.75 \pm 11.94$ & n.s. \\
\hline Problem focused coping & $71.62 \pm 13.27$ & $72.46 \pm 17.02$ & n.s. \\
\hline Emotion focused coping & $69.07 \pm 14.40$ & $67.91 \pm 18.23$ & n.s. \\
\hline Avoidance/resignation/coping & $57.29 \pm 23.47$ & $56.66 \pm 21.95$ & n.s. \\
\hline
\end{tabular}

Abbreviations as in Table 1 .

${ }^{*} \mathrm{Chi}^{2}$ test.

\section{Interpersonal relationship and leadership}

The values of the "social support" dimension were high for physicians $(\mathrm{M} \pm \mathrm{SD}=60.23 \pm 24.9)$ and higher than moderate values in the group of nurses. High values for "social relations" and "a sense of community" categories were determined. Predictability of work tasks was in the normative range, but it was higher for physicians (52.66 \pm 18.79$)$. The results showed well-defined "role clarity," and the scales were significantly higher for the group of physicians (83.26 \pm 13.11$)$. In accordance with the previous studies, values of role conflicts scale were in the moderate range without distinction.

\section{Work-individual interface}

Scales of insecurity at work showed extremely high values for both groups but they were higher among nur- 
ses $(\mathrm{M} \pm \mathrm{SD}=87.36 \pm 6.33)$ as compared to physicians (84.38 \pm 6.76$)$. The category “job satisfaction" for physicians was rated high $(62.61 \pm 12.51)$ and nurses rated it within the highly normative range $(59.83 \pm 15.95)$.

\section{Health, well-being and stress}

The scales of self-rated general and mental health and vitality were within the normative values. The values of mental health scales were slightly higher than in the general health. Values of stress behavior, somatic and cognitive stress reactions scales in both groups were within the range of low values $(<40)$, without statistically significant differences.

\section{Personality}

The scales "sense of coherence" were within high average limits for both groups. The personal resources of the respondents, expressed as values of coping styles scales, which comprehended "problem focused coping" and "emotion focused coping" in all subjects, were within high values $(>60)$. The scales of avoidance - resignation coping for both groups was within the limits of the normative value.

\section{Burnout}

In the Table 4 the values of burnout scores have been presented. The level of personal burnout was high for the group of physicians $(\mathrm{M} \pm \mathrm{SD}=62.08 \pm 18.08)$ as well as for nurses $(56.00 \pm 17.55)$. Work-related burnout was also high for the physicians $(57.76 \pm 20.57)$ and higher than for the group of nurses. Patient-related burnout was high both for physicians $(62.31 \pm 22.13)$ and nurses $(51.93 \pm 26.25)$ with significant differences.

The correlation between values of the COPSOQ scales and burnout scores is shown in the Table 5.

All types of burnout were in direct correlation with quantitative, cognitive and emotional demands, possibilities for career development, behavioral stress, somatic stress and cognitive stress, and in inverse cor- relation with the scales of general health and sense of coherence.

Work-related burnout significantly correlated with the responsibility at work and social relations and in inverse manner with mental health, degree of freedom at work, social support, sense of community and job satisfaction. Patient-related burnout was significantly inverse-correlated with the scale of commitment to the workplace.

Results of the hierarchical multiple regression model of work-related burnout were presented in the Table 6 . The years of physicians' and nurses' work in the EMS $(\beta=0.784, \mathrm{p}<0.001)$, cognitive demands $(\beta=0.042$, $\mathrm{p}<0.001)$, emotional demands $(\beta=0.023, \mathrm{p}<0.01)$, and cognitive stress $(\beta=0.434, \mathrm{p}<0.001)$ were significantly positively associated with work-related burnout. The influence at work $(\beta=-0.285, \mathrm{p}<0.01)$, degree of freedom at work $(\beta=-0.35, p<0.01)$, social support $(\beta=-0.042, p<0.05)$, sense of coherence $(\beta=-0.142$, $\mathrm{p}<0.01)$, mental health $(\beta=-0.46, \mathrm{p}<0.01)$ and problem-focused coping $(\beta=-0.099, \mathrm{p}<0.01)$ were significantly negatively related to work-related burnout. The multifactor linear regression model, which is the independent variable containing the above factors and constant regression, explained $32.2 \%$ of variability values of recent interest $\left(\mathrm{R}^{2}=0.322\right)$.

\section{DISCUSSION}

The current study is the comprehensive approach in order to identify psychosocial risks arising from work stress, individual factors and their relationships of burnout among groups of physicians and nurses employed at the EMS in the city of Niš, the Republic of Serbia.

The high sense of insecurity at work is present especially in the group of nurses; prominent meaning of work is dominantly recognized by physicians, confirming that the current problems in the health care in Serbia result from unsatisfactory economic and staff

Table 4. Burnout measured by the Copenhagen Burnout Inventory (CBI) [13] for the study groups

\begin{tabular}{|c|c|c|c|}
\hline CBI scale & $\begin{array}{l}\text { Physicians } \\
(\mathrm{N}=88) \\
{[\mathrm{pts}]} \\
(\mathrm{M} \pm \mathrm{SD})\end{array}$ & $\begin{array}{l}\text { Nurses/technicians } \\
\qquad \begin{array}{c}(\mathrm{N}=80) \\
{[\mathrm{pts}]} \\
(\mathrm{M} \pm \mathrm{SD})\end{array}\end{array}$ & $\begin{array}{c}\text { Comparison } \\
\text { between } \\
\text { groups }^{*}\end{array}$ \\
\hline Personal burnout & $62.08 \pm 18.08$ & $56.00 \pm 17.55$ & n.s. \\
\hline Work-related burnout & $57.76 \pm 20.57$ & $46.39 \pm 24.01$ & $\mathrm{p}<0.01$ \\
\hline Patient-related burnout & $62.31 \pm 22.13$ & $51.93 \pm 26.25$ & $\mathrm{p}<0.05$ \\
\hline
\end{tabular}

Abbreviations as in Table 1.

* Analysis of variance (ANOVA) and Bonferroni test. 
Table 5. Spearman's rank order correlation between the Copenhagen Psychosocial Questionnaire (COPSOQ) [16] scales and the Copenhagen Burnout Inventory (CBI) scales [13]

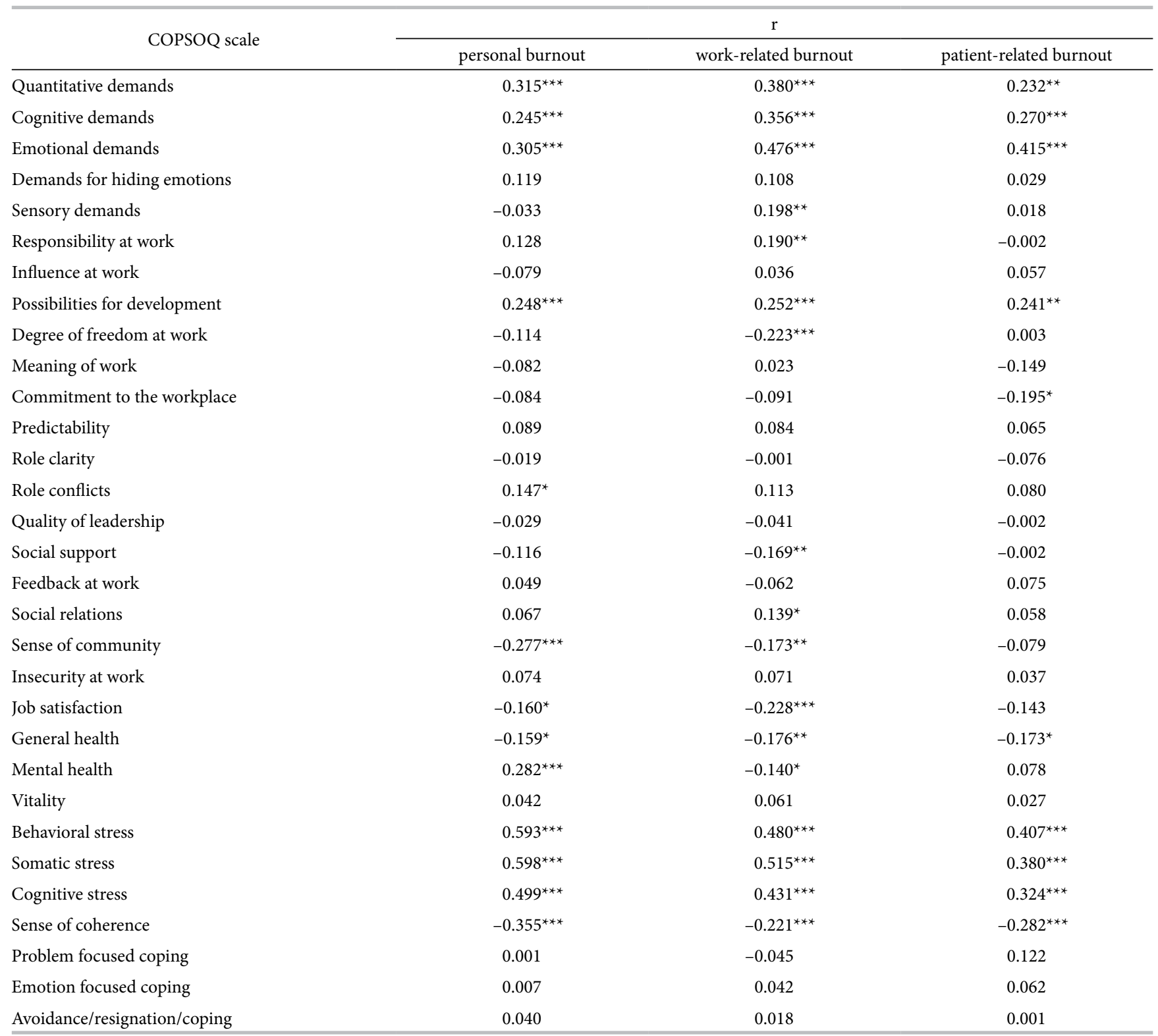

$\mathrm{r}$ - Spearman's rank correlation coefficient.

$* * *$ Statistically significant at $\mathrm{p}<0.001$.

$* *$ Statistically significant at $\mathrm{p}<0.01$

* Statistically significant at $\mathrm{p}<0.05$.

Table 6. Multiple regression analysis of factors influencing the total score of work-related burnout

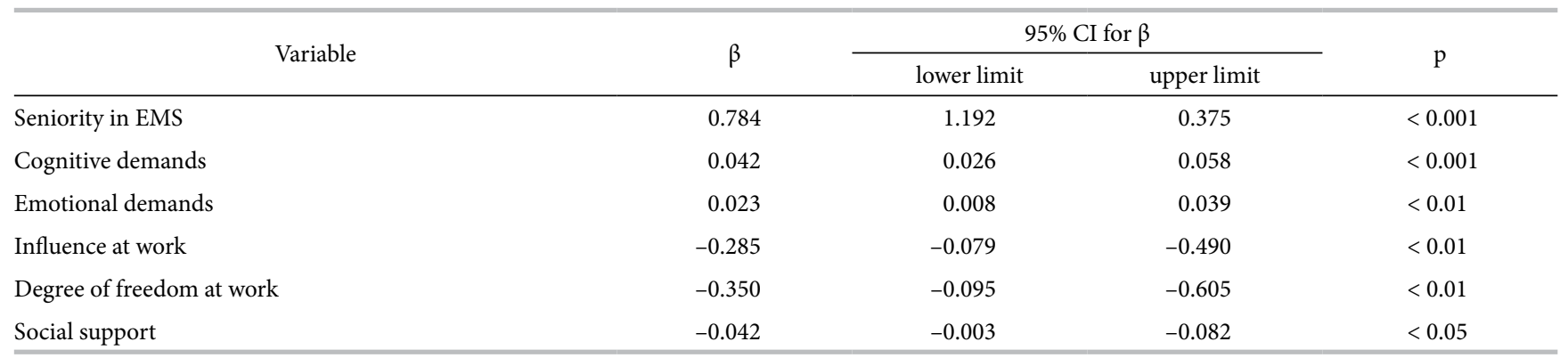


Table 6. Multiple regression analysis of factors influencing the total score of work-related burnout - cont.

\begin{tabular}{|c|c|c|c|c|}
\hline \multirow{2}{*}{ Variable } & \multirow{2}{*}{$\beta$} & \multicolumn{2}{|c|}{$95 \%$ CI for $\beta$} & \multirow{2}{*}{$\mathrm{p}$} \\
\hline & & lower limit & upper limit & \\
\hline Sense of coherence & -0.142 & -0.010 & -0.274 & $<0.01$ \\
\hline Mental health & -0.460 & -0.158 & -0.762 & $<0.01$ \\
\hline Cognitive stress & 0.434 & 0.276 & 0.593 & $<0.001$ \\
\hline Problem focused coping & -0.099 & -0.038 & -0.160 & $<0.01$ \\
\hline $\mathrm{R}^{2}$ & 27.279 & 25.432 & 29.125 & $<0.001$ \\
\hline
\end{tabular}

EMS - Emergency Medical Service.

$\mathrm{R}^{2}$ - constant of regression, $\beta$ - regression coefficient, CI - confidence interval.

rationalization measures, political conditions in the country, less investment in health care, transitional enterprise restructuring, altered dynamics of work, high workload, inadequate working conditions and the lack of new equipment. Changed pathology of the population, decrease in health standards and growing competition among healthcare workers, less safety at work, additionally worsened the problem. Employees in such circumstances are experiencing a lot of pressure at their workplace due to high working demands or do not have enough time to complete the tasks and feel insecure, in spite of giving maximum effort.

The meaning of work represents protective psychosocial factor [14] because it may increase the job and life satisfaction and the work ability. However, in our study the above mentioned conditions, characteristic of the area, time of research and lack of employment possibilities, the high meaning of work may be a risk factor related to occupational stress and it may affect mental and physical health of the EMS staff and their quality of life [4].

Occupational stress in the emergency medicine is usually attributed to the specific working conditions $[9,18]$. Fieldwork, fast intervention and small degree of autonomy during a brief contact with patients are associated with a wide spectrum of stress effects. In this study, we have identified psychosocial risks of emergency physicians which have occurred due to high cognitive, emotional, sensory and quantitative demands, great responsibility for the health and lives of the others, making quick and difficult decisions, need for prompt reaction, specific knowledge and skills, overload due to numerous obligations and concerns about making unintentional errors, which corresponds to the results of other authors [19]. These situations are often emotionally exhausting and they necessitate sudden energy supply, intensive thoughts and actions, un- divided concentration and attention to current events. In these circumstances, actual experiences tend to become isolated events and normal cognitive and emotional mechanisms become ineffective, which in longterm period leads to burnout with the potential to reduce the ability of coping crisis events or beyond it in personal life $[17,20]$.

According to Karasek's model of work stress, nurses are among high cognitive and sensory demands and with a low degree of freedom at work [4,21], which has already been assessed in our study. Lack of autonomy, numerous duties, great meaning and commitment to work, less social support and lack of feedback at work in this study have also proven significant psychosocial risks of emergency nurses. In addition, the occupational stress of nurses is connected with the strict hierarchical control in complex organizational relations network, demands for performing tasks upon the orders of the physician, the head nurses, working with patients and additional administrative work. It seems to be consistent with the fact that the presence of stress due to changing the hierarchy of relevance diminishes job satisfaction and has a negative effect on the general and mental health, the aggravation of interpersonal relationships and generating new stressors and behavioral reactions, considering previously stated positive correlation between these psychosocial factors and work-related burnout.

Emergency physicians are affected by personal, work-related, and patient-related burnout, while nurses showed high personal and patient-related burnout. Burnout levels in our study are significantly higher than in the other studies to which the same methodology and target groups were applied $[2,17,19]$.

In this research, emotional, cognitive, quantitative work demands in the EMS correlated with high burnout values in all 3 categories; sensory demands also 
correlated with patient-related burnout. However, the demands for hiding emotions were within moderate values and were not connected with burnout, therefore, it may only refer to the specific nature of emotions at work [20] in emergency medicine, including automatic regulation of emotions or empathy, and burnout in this research as compassion fatigue [22]. We also confirm that each working year in the EMS, physicians and nurses increased the severity of work-related burnout, but better influence at work, higher degree of freedom at work and good social support are protective psychosocial factors with negative interrelationships of workrelated burnout.

The emergence of burnout may depend on the manner how the employees understand stressful situations and its development at the same time. Subjective feeling of overload, fatigue and difficulty in working with patients are associated with burnout and psychiatric morbidity [23]. We have determined that high commitment to the workplace of physicians and nurses in the EMS may represent a protective factor in relationships with patient-related burnout. Job satisfaction, commitment to work as well as the meaning of work, could have a potential protective character, considering inverse correlation with a personal and work-related burnout of physicians and nurses in our study.

Besides high work demands, behavioral, cognitive and somatic stress, as predictors of burnout, were found as possibilities for career development, which represents favorable psychosocial factors for most employees. These facts may be interpreted as characteristic for the physicians' and nurses' profession, and most recently characteristic for other professions, having necessity of continuous improvement knowledge and skills. Increased possibilities for development lead to the increasing number of obligations or work-family conflict. It could encourage competition and careerism among employees, and therefore it represents a risk factor for the development of occupational stress and burnout.

The specific stressors and organizational working conditions in the EMS are more correlated with the frequency of occupational stressors related to the individual characteristics, while general relations between stress at work and individual characteristics are very weak [18]. However, individual characteristics of our respondents were expressed through the experience of stress and response to stress, coping strategies, self-rated health and vitality, a sense of community, sense of coherence and social support which showed a favorable value. Within this research, it mostly applies to the physicians, as bearers of the work in emergency units, where the highest levels of psychosocial risks were determined.

Personal resources such as a sense of coherence have been found to be linked to burnout $[18,19]$. We found that sense of coherence negatively related with the severity of burnout. People with a stronger sense of coherence seek for strategies that are focusing on the problem, and they are determined as the protective factor in relation to work-related burnout emergency physicians and nurses. The salutogenic concept [24] suggests that having a high sense of coherence is associated with the ability to eliminate sources of stress and following anxiety, which could prevent consequences to the health. Over the time, people with a strong sense of coherence will experience short-term harmful effects of psychosocial risks. They are more flexible in the choice of strategies and they have skills of using empirical data in solving problems, but sense of coherence is not a specific manner of coping with stress.

The strategies of coping with stress involve avoiding habits and behavior that directly affect health and may reduce severity of illness consequences. When it comes to the utilization of coping, problem-focused coping is strongly influenced by the context, while emotionfocused coping is under increasing influence of personal factors. Lazarus and Folkman [7] favor the measurement of the coping in a specific stressful situation because the preferred ways of coping will likely manifest themselves in the same or similar situations as referred to in this research. In unclear and/or in a new situation, when the signs from the surrounding are minimal or can't be clearly interpreted, individual's nature has a greater role in cognitive appraisal and in the selection of the manner of coping strategies related to surroundings factors. The influence of the environment [25] is the largest in the cases of drastic situations occurrence such as natural disasters, sudden death or critical incidents.

The complexity of situations which employees face in helping professions, according to the available empirical literature, suggests that the relationship between strategies of coping, burnout and mental health of a helper is quite repugnant $[3,8,18]$. In the nursing profession Fearon and Nicol [26] found a negative correlation between task-orientated, i.e., problem-focused coping and the severity of burnout. Additionally, they found that this coping style was preferable under poor organizational conditions Task-oriented coping was associated with decreased risk of burnout, while emotion-oriented 
coping was associated with increased risk of burnout for healthcare professionals in a large Canadian study emergency department [27]. Problem-focused coping is a good indicator of compassion satisfaction but it is not correlated to compassion fatigue or burnout [28]. However, our study results suggest any different interrelationships. The results of the analysis in our study confirm the predictions concerning the positive effects of problem-focused coping of the work-related burnout symptoms [28].

It seems that it is possible that our participants' existing coping styles in respect of everyday stressors may, despite the increased work demands and psychosocial risks, maintain stress response at low limits for both groups (physicians and nurses) in the EMS. The avoidance coping occurrences are significant predictors of decreasing compassion satisfaction and increasing in compassion fatigue and burnout, according to some authors $[29,30]$, but it hasn't been confirmed in our study, i.e., high scores of burnout have not correlated to avoidance.

\section{Limitations of the study}

Within the study, characteristics of participants' personality and temperament were not obtained using appropriate psychometric instruments. Reports on the health of participants are based on self-reporting of their current health conditions and health disorders. As it was a cross-sectional study performed, no data was available of the possible recent work incidents or the current work environment circumstances could have influenced the obtained data.

\section{CONCLUSIONS}

In the observed population of emergency physicians and nurses, the significant correlation between work demands, possibility of control, social support, stress reactions and the work-related burnout exists. Favorable psychosocial factors, mostly social relations, role clarity, job satisfaction and the employees' personality, expressed through strategies of coping with stress, a sense of community and sense of coherence, have the significant effect on the decreasing burnout.

Based on individual factors and coping with stress, both physicians and nurses in the emergency medical service represent the self-selective professional group exposed to events beyond the usual human experience, facing high work demands, great responsibility, strong commitment to the workplace, insecurity and small degree of freedom at work. However, they may handle within wide limits of acute and chronic stress at work. High levels of physicians' and nurses' burnout in the emergency services tend to be an acceptable norm with the risk of being ignored, in spite of severe consequences on their mental and general health.

\section{Implications}

Physicians and nurses in the EMS, due to specific work demands and repeated exposure to the stressors, can't avoid further trauma unless they leave or change the job $[5,19]$. Therefore, the purpose of this study has been to establish preventive measures on time, when this kind of occupation still doesn't cause severe effect on the health and effectiveness of employees. Timely and adequate support and management of the necessary knowledge and skills could provide effective results. It is also a clear signal for applying the health promotion programs in the workplace in order to improve personal resilience strategies, critical stress incident management, time management, assertiveness training and emotional intelligence, in cooperation with experts in these fields. There is the necessity for developing a healthy working atmosphere, based on support, feedback at work, good communication and efficient conflicts resolving.

An important implication arising from this study is the fact that health organizations, majority of medical educational institutions should carry out adequate candidates' professional orientation and selection in order to facilitate work roles based on the self-concept, personality, interests and skills. In this manner, positive effects of work in the emergency services will be maximized, and the consequences of the necessary choices and risks such as work-related stress, burnout and job dissatisfaction, in this important profession, will be prevented.

\section{REFERENCES}

1. Leka S, Griffiths A, Cox T. Work Organization and Stress. Protecting workers' health series No. 3 [Internet]. Geneva: World Health Organization; 2004 [cited 2016 Sep 6]. Available from: http://www.who.int/occupational_health/publications/pwh3rev.pdf?ua $=1$.

2. Arandjelovic M, Nikolic M, Stamenkovic S. Relationship between burnout, quality of life, and work ability index Directions in prevention. Sci World J. 2010;10:766-77, https://doi.org/10.1100/tsw.2010.83.

3. Pejušković B, Lečić-Toševski $\mathrm{D}$, Priebe $\mathrm{S}$, Tošković $\mathrm{O}$. Burnout syndrome among physicians - The role of per- 
sonality dimensions and coping strategies. Psychiatr Danub. 2011;23(4):389-95.

4. Freimann T, Merisalu E. Work-related psychosocial risk factors and mental health problems amongst nurses at a university hospital in Estonia: A cross-sectional study. Scand J Public Health. 2015;43(5):447-52, https://doi. org/10.1177/1403494815579477.

5. Pantenburg B, Luppa M, König H-H, Riedel-Heller SG. Burnout among young physicians and its association with physicians' wishes to leave: Results of a survey in Saxony, Germany. J Occup Med Toxicol. 2016;11:2, https://doi. org/10.1186/s12995-016-0091-z.

6. Arandjelovic M. A need for holistic approach to the occupational health developing (in Serbia). Int J Occup Med Environ Health. 2011;24(3):229-240, https://doi.org/10. 2478/s13382-011-0033-z.

7. Lazarus RS, Folkman S. Stress, appraisal, and coping. New York: Springer; 1984.

8. Sterud T, Ekeberg Ø, Hem E. Health status in the ambulance services: A systematic review. BMC Health Serv Res. 2006;6:82, https://doi.org/10.1186/1472-6963-6-82.

9. Wieclaw J, Agerbo E, Mortensen PB, Bonde JP. Risk of affective and stress related disorders among employees in human service professions. Occup Environ Med. 2006;63:314-9, https://doi.org/10.1136/oem.2004. 019398.

10. Auxéméry Y. [Posttraumatic stress disorder (PTSD) as a consequence of the interaction between an individual genetic susceptibility, a traumatogenic event and a social context]. Encephale. 2012;38(5):373-80, https://doi. org/10.1016/j.encep.2011.12.003. French.

11. Shipley F, Gow KM. State Emergency Service (SES) volunteer members: An investigation into coping abilities and adjustment strategies following emergency activations. Australas J Disaster Trauma Stud. 2006;1:1-9.

12. Schaufeli WB, Leiter MP, Maslach C. Burnout: 35 years of research and practice. Career Dev Int. 2009;14(3):204-20, https://doi.org/10.1108/13620430910966406.

13. Kristensen TS, Borritz M, Villadsen E, Christensen KB. The Copenhagen burnout inventory: A new tool for the assessment of burnout. Work Stress. 2005;19:192-207, https:// doi.org/10.1080/02678370500297720.

14. Nuebling M, Seidler A, Garthus-Niegel S, Latza U, Wagner M, Hegewald J, et al. The Gutenberg Health Study: Measuring psychosocial factors at work and predicting health and work-related outcomes with the ERI and the COPSOQ questionnaire. BMC Public Health. 2013; 13:538, https://doi.org/10.1186/1471-2458-13-538.

15. Pejtersen JH, Kristensen TS, Borg V, Bjorner JB. The second version of the Copenhagen Psychosocial Question- naire. Scand J Public Health. 2010;38 Suppl 3:8-24, https:// doi.org/10.1177/1403494809349858.

16. Kristensen TS, Hannerz H, Høgh A, Borg V. The Copenhagen Psychosocial Questionnaire - A tool for the assessment and improvement of the psychosocial work environment. Scand J Work Environ Health. 2005;31(6):438-49, https:// doi.org/10.5271/sjweh.948.

17. Borritz M, Rugulies R, Bjorner JB, Villadsen E, Mikkelsen OA, Kristensen TS. Burnout among employees in human service work: Design and baseline findings of the PUMA study. Scand J Public Health. 2006;34(1):49-58, https://doi.org/10.1080/14034940510032275.

18. Sterud T, Hem E, Ekeberg $\varnothing$, Lau B. Occupational stressors and its organizational and individual correlates: A nationwide study of Norwegian ambulance personnel. BMC Emerg Med. 2008;8:16, https://doi.org/10.1186/1471-22 7X-8-16.

19. Estryn-Behar M, Doppia MA, Guetarni K, Fry C, Machet G, Pelloux P, et al. Emergency physicians accumulate more stress factors than other physicians-results from the French SESMAT study. Emerg Med J. 2011;28(5):397-410, https://doi.org/10.1136/emj.2009.082594.

20. Zapf D, Seifert C, Schmutte B, Mertini H, Holz M. Emotion work and job stressors and their effects on burnout. Psychol Health. 2001;16(5):527-45, https://doi.org/ $10.1080 / 08870440108405525$.

21. Milutinović D, Grujić N, Jocić N. [Identification and analysis of stress factors at nursing workplace: A comparative study of four clinical departments]. Med Pregl. 2009; 62(1-2):68-73, https://doi.org/10.2298/MPNS0902068M. Serbian.

22. Stamm BH. Helping the helpers: Compassion satisfaction and compassion fatigue in self-care, management, and policy. In: Kirkwood AD, Stamm BH, editors. Resources for community suicide prevention [CD]. Meridian, Pocatello (ID): Idaho State University; 2012.

23. Kumar S, Hatcher S, Huggard P. Burnout in psychiatrists: An etiological model. Int J Psychiatry Med. 2005; 35(4):405-16, https://doi.org/10.2190/8XWB-AJF4-KPR R-LWMF.

24. Benz C, Bull T, Mittelmark M, Vaandrager L. Culture in salutogenesis: The scholarship of Aaron Antonovsky. Glob Health Promot. 2014;21(4):16-23, https://doi. org/10.1177/1757975914528550.

25. Parker JDA, Endler NS. Coping with coping assessment: A critical review. Eur J Pers. 1992;6:321-44, https://doi. org/10.1002/per.2410060502.

26. Fearon C, Nicol M. Strategies to assist prevention of burnout in nursing staff. Nurs Stand. 2011;26:35-9, https://doi. org/10.7748/ns2011.12.26.14.35.c8859. 
27. Howlett M, Doody K, Murray J, LeBlanc-Duchin D, Fraser J, Atkinson PR. Burnout in emergency department healthcare professionals is associated with coping style: A cross-sectional survey. Emerg Med J. 2015;32:722-7, https://doi.org/10.1136/emermed-2014-203750.

28. Nowakowska-Domagala K, Jabłkowska-Górecka K, Kostrzanowska-Jarmakowska L, Mortoń M, Stecz P. The interrelationships of coping styles and professional burnout among physiotherapists: A cross-sectional study. Medicine (Baltimore). 2015;94(24):e906, https://doi.org/10.1097/MD. 0000000000000906.
29. Prati G, Pietrantoni L, Cicognani E. Coping strategies and collective efficacy as mediators between stress appraisal and quality of life among rescue workers. Int J Stress Manag. 2011;18(2):181-95, https://doi.org/10.1037/a0021298.

30. Kirby R, Shakespeare-Finch J, Palk G. Adaptive and maladaptive coping strategies predict posttrauma outcomes in ambulance personnel. Traumatology. 2011;17(4):25-34, https://doi.org/10.1177/1534765610395623.

This work is available in Open Access model and licensed under a Creative Commons Attribution-NonCommercial 3.0 Poland License / Ten utwór jest dostępny w modelu open access na licencji Creative Commons Uznanie autorstwa - Użycie niekomercyjne 3.0 Polska - http://creativecommons.org/ licenses/by-nc/3.0/pl/deed.en. 